\title{
Development and Replication of Effective Projects for the Organization of Medical Care by the Example of Mining Region Kuzbass
}

\author{
Galina Tsarik ${ }^{1}$, Olga Barkova $^{2}$, and Tatiana Gracheva ${ }^{3}$ \\ ${ }^{1}$ Kemerovo State Medical University of the Ministry of Health of the Russian Federation, Head of the \\ Department of Public Health and Health Care, 650029, 22a Voroshilova st., Kemerovo, Russia \\ ${ }^{2}$ Regional Center for the Organization of Primary Health Care, Center Head \\ ${ }^{3}$ Kuzbass Clinical Psychiatric Hospital, Deputy Chief Physician, 650036, 41 Volgogradskaya st., \\ Kemerovo, Russia
}

\begin{abstract}
The aim of the study is to develop technologies for operational management of processes and projects that increase the efficiency of medical organizations by replicating automated systems of "hyperresonant solutions" and monitoring achievements to improve activities aimed at improving the quality and availability of medical care. The object of researching the control mechanism is represented by 104 medical organizations of primary care, introducing lean technologies. The study of the current state of accessibility, satisfaction and quality of medical care was carried out by the method of direct observation and timing of receiving medical services by patients. To ensure the optimization of management on the basis of materials characterizing the current state of accessibility, satisfaction and quality of medical care, it was supposed to form a process model of the organization, including a classifier of activities. The use of a system analysis matrix, MS Excel tables and hyperlinks contributed to the definition of priorities and the development of improvement projects, which ensured the formation of management algorithm for the organization development.
\end{abstract}

\section{Introduction}

The health of citizens, as a social-and-economic category, predetermines and forms the labor potential of society, representing the most important element of the country's national wealth [1].

The priority tasks of health care include the solution of issues of accessibility and quality of medical care, the development of a preventive direction, and an increase in the efficiency of the activities of medical organizations [2].

The purpose of organizing medical care is to ensure the quality and availability of its provision and receipt. In Kuzbass, many projects are being developed using lean technologies that contribute to achieving this goal.

Nowadays a number of problems require reflection and solution in medicine [3]. They are the lack of accessibility of medical services, a long wait for medical investigation and 
consultations, an unreasonably large number of visits in the process of age-specific dispensary examination and examination before planned hospitalization. The presence of long queues at the registry, nursing post, low patient satisfaction with the organization of medical care negatively affect the provision of medical care $[4,5]$.

Increasing the efficiency of the provision of medical services at the outpatient stage, the Ministry of Health of the Russian Federation recommends the introduction of lean production technologies and the replication of the "New model of organization providing primary health care" $[6,7,8]$.

The replication of effective projects implemented in the context of specific medical organizations to achieve large-scale transformations in the healthcare sector deserves to be widespread. This approach ensures getting the planned result of improving the production and provision of medical services in organizations being in need of improving the activity by repeating previously implemented effective projects on the basis of other medical organizations [9].

The government of the Russian Federation has set ambitious goals for healthcare $-70 \%$ of all polyclinics should become "lean" by 2025. The leading role in improving the quality of life with the use of new technologies is assigned to the regions $[10,11]$. In the medical and educational sphere, various mechanisms are used to improve the quality of services provided; most of them are associated with digitalization and lean technologies [12, 13, 14, 15].

Since August 2018, the federal project "Development of the primary health care system" has been implemented in Kuzbass. Under the implementation plan for "New model of medical organization" approved by the Ministry of Health of the Russian Federation, the introduction of lean technologies in primary care organizations is expected to increase from 2 polyclinics in 2018 to 168 in 2024.

The introduction of lean technologies will make it possible to ensure the availability and provision of high-quality medical care with the available limited financial and human resources in conditions of a shortage of premises due to the following:

- reduction of all types of losses (waiting, waste, overproduction of services, unnecessary transportation, unnecessary movements);

- ensuring an even balanced distribution of functional responsibilities between employees;

- formation of rational patient flows depending on the purpose of visiting and effective use of the premises of medical organizations;

- optimization of information flows, including improving the efficiency of the medical information system,

- standardization of treatment and diagnostic processes based on "best practices" and reducing their variability.

The use of lean production technologies in medical organizations makes it possible, by reducing losses and rational organization of work, to use the available resources more efficiently [16].

Achieving the criteria of the "New model of the polyclinic" requires identifying the processes that need to be improved and the implementation of projects aimed at improving them.

\section{Materials and Methods}

The research object of the management mechanism is represented by 104 primary health care organizations that implement lean technologies. The study of the current state of accessibility, satisfaction and quality of medical care was carried out by the method of direct observation and timing of receiving medical services by patients. The survey covered the flow of patients seeking medical care and medical personnel providing assistance. 720 patients, 470 doctors and 450 paramedics were interviewed. The questionnaires' filling in was carried out 
in accordance with the informed consent of the respondents. Blocks of questions made it possible to evaluate the following:

- the material and technical base of the organization;

- availability of medical care;

- the quality of medical services;

- the culture of medical service;

- the level of visual helpful information;

- order and cleanliness;

- drug supply;

- patient satisfaction with care;

- problems of the organization from the point of view of patients and employees;

- the desire of patients to go to another place within the compulsory medical insurance and change the district doctor;

- the structure of patient encounters to a medical organization and the need for assistance;

- the possibility and availability to apply to other medical institutions;

- the types of services not available to patients.

To ensure optimization of management based on materials characterizing the current state of accessibility, satisfaction and quality of medical care, a process model of the organization has been developed, including a classifier of activities.

The system analysis matrix contributed to the definition of priorities and the creation of projects to increase the amount of knowledge of personnel in the field of lean production, and the motivation of medical organizations' employees to implement lean technologies. It also contributed to correcting the staff shortage, increasing activity in replicating projects, and developing measures related to an unfavorable epidemiological situation connected with the COVID-19 pandemic.

The system of monitoring the criteria achievement (SMCA) of a new polyclinic model ensured the timely adoption of corrective management decisions.

\section{Results and Discussions}

The questionnaire survey and timing of receiving medical care ensured a management system development for medical organizations using lean technologies (MSMO).

The Federal Service for Intellectual Property "ROSPATENT" registered the procedure of management system development for medical organizations (MSMO) (registration number 2021620330).

The algorithm for managing the medical organization development represents a "hyperresonant solution" and is formed based on defining the organization's mission, its goals and objectives; development of activity process model with a process classifier; substantiation of the project for the development of the organization for a long-term period with the subsequent implementation of the stages:

- opening and drawing up a project passport;

- assessment of the situation;

- mapping of a continuous flow of patients;

- analysis of problems and losses;

- drawing up a map of the target and ideal state;

- developing an action plan;

- order of project presentation;

- implementation of improvements;

- monitoring of results;

- stage-by-stage assessment of achievements;

- monitoring the stability of results. 
Monitoring the achievements of a long-term project provides a stage-by-stage assessment of the implementation of planned activities. Accomplishment is the achievement of the expected stable result.

The building blocks of a long-term project are represented by lean projects aimed at improving processes and solving the most urgent problems. The term lean project means the concept of managing a production enterprise, which is based on the constant striving to eliminate all types of losses [6].

MSMO allows in automatic mode building, in accordance with the timing data, maps of the current and target states, a Gantt chart (action plan), to monitor the timing of activities' implementation. It contains the stages of sequential actions for the opening and implementation of the project, including theoretical part (for each of the sections), and documents for practical use.

We developed the process model of polyclinic in accordance with the documents: the federal law "On the basics of protecting the health of citizens in the Russian Federation" dated November 21, 2011 No. 323-FL, "GOST R ISO 9001-2015 National standard of the Russian Federation. Quality management systems. Requirements" approved by order of Rosstandart dated September 28, 2015 No. 1391-st together with "Clarification of new structure, terminology and concepts", "Other international standards in the field of quality management and the quality management system developed by ISO / TC 176", and the program of state guarantees for the provision of free medical care to citizens. In addition, we considered volumetric and financial indicators of the activities of organizations, the study of the current state of accessibility, satisfaction and quality of medical care. The process model of polyclinic include the following:

- processes of the life cycle of medical care;

- management processes;

- resource provision processes;

- processes of monitoring, measuring, analyzing and evaluating the activities of a medical organization.

Before the development of the process model of polyclinic, its activities were not structured and were presented as separate types, which complicated the management processes and required optimization.

The lean production projects, the creation of "hyperresonant solutions" aimed at reducing the temporary loss of patients in the process of receiving medical services and the implementation of $5 \mathrm{C}$ system at the workstations of personnel, taking into account sorting technologies, compliance with order, cleanliness, standardization processes of operations, improvement of order and discipline with monitoring the results in the process of questioning and implementation of improvement projects before and after their implementation allow us stating the following:

- reduction of time for the preventive examination of children in 14 times from 14.1 to 1.0 days $(\mathrm{P}=0.001)$;

- decrease in the duration of medical examination in 2.7 times from 8.0 to 3.0 days $(\mathrm{P}=$ $0.002)$;

- reduction of the waiting time for the vaccination procedure at the vaccination room in 2.6 times from $117.0 \mathrm{~min}$. up to $45.3 \mathrm{~min}$. ( $\mathrm{P}=0.001)$;

- reduction of waiting time at the treatment room in 7.7 times from 120.5 minutes to 15.5 minutes. $(\mathrm{P}=0.001)$;

- increase in the population's satisfaction with the work of the registry in $45.2 \%$ from $42.1 \%$ to $87.3 \%(\mathrm{P}=0.001)$;

- reduction of equipment downtime in physiotherapy departments in 10.5 hours from 12.5 hours to 2.0 hours $(\mathrm{P}=0.001)$. 
The study of the problem of ensuring the availability and quality of medical care, the development of a preventive direction, and an increase in the efficiency of the activities of medical organizations does not lose its relevance, which was the reason for this study [17].

The scientific literature discusses the problems of the industry and proposes various options for solutions, including an analysis of the frequency of hospitalizations in third-level institutions, an assessment of the success of an institution's management decisions, taking into account the frequency and volume of primary care $[18,19]$. Optimization of the management processes in medical organizations using digital technologies is of particular importance. Increasing the efficiency of information exchange between doctors and nurses is of great importance [20].

However, the use of the process approach in medical organizations management with the use of information technologies based on "hyperresonant solutions" and lean manufacturing is not well covered in the literature.

The relevance of widespread replication of "hyperresonant solutions" is determined by the fact that the process of implementing approved developed projects is less laborious. It is easier to replicate and adapt than redevelop. The term for obtaining results is shortened. The staff of a medical organization quickly achieves its goal, which motivates employees and reduces resistance to change, and increases satisfaction with achievements. Improvement projects in the process of their transformation into other organizations require some effort, and this is far from an easy task.

The experience of Kuzbass healthcare has contributed to identifying the reasons for the ineffective replication of projects. They are:

- adaptation can be difficult due to significant differences in the conditions of medical care; - medical organizations are not always ready to share their experience;

- there is no unification in the design of projects;

- low quality of standardization based on the results of the projects improving traditional technologies for organizing medical care;

- the lack of understanding the basics of replication by the staff and lack of replication skills.

Improvement of individual processes did not allow assessing the dynamics and degree of achievement of the criteria of "New model of polyclinic", to have a holistic picture of its development.

Therefore, there was a need to create a tool allowing the elaboration of a long-term project for organization development, providing on-line monitoring, monitoring the timing of projects and making management decisions on-line using information technologies based on "hyperresonant solutions".

Taking into account the foregoing, a mechanism for optimizing management using "hyperresonant solutions" that ensures the development of medical organizations based on the formation of new competencies, providing knowledge of the process approach and lean technologies through the implementation of lean projects and the formation of a new model for organizing medical care is presented.

The study found that at the time of implementation of lean production technologies, 40.5 $\pm 0.4 \%$ of employees of medical organizations knew about lean production of services. The lack of knowledge about the basics of lean production was filled through measures on correction the situation with the participation of specialists from the ROSATOM State Corporation, the Ministry of Health of Russia, educational institutions of Kuzbass, the Regional Center for Primary Health Care and the Regional Competence Center of Kuzbass. More than 500 employees of medical organizations were trained; 5 factories of processes were opened, including "Pre-care encounter", "Treatment room", "5C", "Conducting a meeting using SQDCM", "Clinical examination", training "Referral for planned hospitalization". The publication of a study guide and organization of testing those responsible for the implementation 
of lean technologies contributed to an increase in the competence of employees of medical organizations on issues of lean production to $80.1 \pm 0.8 \%$.

Before the introduction of lean technologies in the treatment and diagnostic process of medical organizations, only $30.3 \pm 0.6 \%$ were in favor of the proposed projects. In order to motivate employees of medical organizations to introduce lean technologies, regular excursions to clinics that most successfully implement lean technologies and have experience of best practices were organized. An important place was given to stimulating employees in the framework of project implementation. As a result of the measures taken, $85.4 \pm 0.7 \%$ supported the introduction of lean technologies. Since November 2020, all 225 polyclinics have started their implementation.

The study of medical organizations staffing showed the problem of a personnel shortage. Its solution was carried out through the development and implementation of projects that allow using internal reserves, reducing wasted time and equipment downtime.

Currently, in Kuzbass, the development of projects aimed at increasing the efficiency of medical organizations through replication is carried out using the technologies of "hedgehog fair", which help:

- to create a project for replication, during the development of which the peculiarities of the conditions and the variety of problems of the participants are taken into account, various ways of solutions are considered;

- to test the project at various medical organizations;

- to improve the project taking into account the comments of a wide range of institutions;

- to use for replication the projects approved by the Ministry of Health of the Kemerovo Region.

Preparing the environment for replication involves:

- motivation of personnel to exchange experience, including holding an open day, encouraging personnel;

- increasing the prestige of medical organizations by organizing regional competitions for the best improvement projects;

- improving the quality of projects by creating samples of medical organizations according to the methodology of State Corporation "ROSATOM"

Monitoring the number of replicated projects based on questionnaires and correcting their insufficiently active replication using "hyperresonant solutions" and classifier of improvement projects implemented in medical institutions of the region, based on the list of criteria for achieving the "New model of organization providing primary health care", it was possible to increase the considered indicator from five to fifteen projects.

Restrictive measures related to the unfavorable epidemiological situation connected with COVID-19 led to the transition to a remote format of consulting, training, auditing using video lectures on lean manufacturing tools, consideration and approval of 179 passports of lean projects on improvements. The results of the lean projects have proved the effectiveness of the activities carried out.

Since 2020, the implementation of improvement projects, monitoring of the results achieved is carried out using the MSMO, which contributes to the transition from individual projects to a single model of polyclinic.

\section{Conclusion}

The development of technologies for the operational management of processes and projects that increase the efficiency of medical organizations through the use of automated systems " hyperresonant solutions" and monitoring the achievements of activities aimed at improving the quality and availability of medical care contributed to the reduction of time losses for patients receiving medical care, and increasing the efficiency of using the equipment, which 
confirms the achievement of the research goal. The presented organizational technologies are recommended for management of medical organizations development.

\section{References}

1. Yu.T. Sharabchiev, International Reviews: Clinical Practice and Health, 5(11), 132-151 (2014)

2. A.I. Vyalkov, G.P. Skvirskaya, Healthcare Manager, 22, 13-19 (2015)

3. I.V. Ivanov, V.A. Belenkaya, D.F. Taut, A.G. Tolkacheva, Quality management in medicine, 1, 34-37 (2019)

4. G. Tsarik, T. Gracheva, A. Aleshina, E. Tkacheva, Medical Law: Theory and Practice, 4(8), 81-85 (2018)

5. M.A. Kantemirova, Z.R. Alikova, Bulletin of the North Ossetian State University, 1, 9295 (2019)

6. J.P. Wumek, D.T. Johns, Lean Thinking: Banish waste and create wealth in your corporation (Al'pina Pablisher, Moscow, 2011)

7. K.Yu. Kitanina, A.G. Lastovetskiy, Bulletin of new medical technologies, 2, 114-121 (2018)

8. S.V. Polyanskaya, Bulletin of the Volga Region Academy of Public Administration, 3(28), 132-136 (2011)

9. M.G. Khafizov, Implementation of a process approach to achieve the strategic goals of medical organizations (Moscow, 2014)

10. N.V. Gorodnova, N.A. Samarskaya, A.V. Krupkin, I.S. Rozhentsov, Economics and Entrepreneurship, 5(106), 475-483 (2019)

11. Yu.V. Shmarion, O. V. Goloshchapova, Socio-economic phenomena and processes, 14:2(106), 5-16 (2019)

12. E.I. Aksenova, Analytical Bulletin of the Federation Council of the Federal Assembly of the Russian Federation, 9(752), 21-27 (2020)

13. K.K. Davlatzoda, S.Sh. Sharipov, Financial and Economic Bulletin, 3(19), 21-27 (2019)

14. A.V. Evseenko, V.V. Kuleshov, G.A. Untura, Modernization of the sectors of scientific, educational and innovative activities in Siberia (IEIE SB RAS, Novosibirsk, 2014)

15. P.A. Levchaev, Economy of the XXI century: innovation, investment, education, 6(2), 40-56 (2018)

16. M.G. Khafizov, Siberian Financial School, 4(123), 112-119 (2017)

17. S.L. Pisarev, O.E. Rautsky, Informatization in health care as an analytical basis for support of managerial decisions (Tver, 2017)

18. L.N. Sviderskaya, V.M. Simacova, V.T. Hendogina, F.P. Chavkunkin, Siberian medical review, 3(93), 97-101 (2015)

19. A. N. Pukhalsky, Organizational and economic principles and approaches to the development of high-tech medical services in the Russian Federation (RANHIGS, Moscow, 2015)

20. N. Knyazyuk, Healthcare, 9, 52-65 (2017) 